\title{
Vestibular migraine in children and adolescents: clinical findings and laboratory tests
}

\author{
Thyra Langhagen ${ }^{1,2}{ }^{*}$, Nicole Lehrer ${ }^{1}$, Ingo Borggraefe ${ }^{1,2}$, Florian Heinen ${ }^{1,2}$ and Klaus Jahn ${ }^{1,3}$ \\ 1 German Center for Vertigo and Balance Disorders, Ludwig-Maximilians-University of Munich, Munich, Germany \\ ${ }^{2}$ Department of Pediatric Neurology and Developmental Medicine, Ludwig-Maximilians-University of Munich, Munich, Germany \\ ${ }^{3}$ Schön Klinik Bad Aibling, Bad Aibling, Germany
}

\section{Edited by:}

Mark Obermann, University Hospital

Essen and University of

Duisburg-Essen, Germany

Reviewed by:

Stefan Evers, University of Münster, Germany

Elcio J. Piovesan, Universidade Federal do Paraná, Brazil

*Correspondence:

Thyra Langhagen, German Center for Vertigo and Balance Disorders, Ludwig-Maximilians-University of Munich, Klinikum Grosshadern, Marchioninistr. 15, Munich 81377, Germany

e-mail: thyra.langhagen@med. uni-muenchen.de
Introduction: Vestibular migraine (VM) is the most common cause of episodic vertigo in children. We summarize the clinical findings and laboratory test results in a cohort of children and adolescents with VM. We discuss the limitations of current classification criteria for dizzy children.

Methods: A retrospective chart analysis was performed on 118 children with migraine related vertigo at a tertiary care center. Patients were grouped in the following categories: (1) definite vestibular migraine (dVM); (2) probable vestibular migraine (pVM); (3) suspected vestibular migraine (sVM); (4) benign paroxysmal vertigo (BPV); and (5) migraine with/without aura (oM) plus vertigo/dizziness according to the International Classification of Headache Disorders, 3rd edition (beta version).

Results: The mean age of all patients was $12 \pm 3$ years (range $3-18$ years, 70 females). 36 patients (30\%) fulfilled criteria for dVM, 33 (28\%) for pVM, $34(29 \%)$ for sVM, 7 (6\%) for BPV, and $8(7 \%)$ for oM. Somatoform vertigo (SV) co-occurred in $27 \%$ of patients. Episodic syndromes were reported in $8 \%$; the family history of migraine was positive in $65 \%$. Mild central ocular motor signs were found in $24 \%$ (most frequently horizontal saccadic pursuit). Laboratory tests showed that about $20 \%$ had pathological function of the horizontal vestibulo-ocular reflex, and almost $50 \%$ had abnormal postural sway patterns.

Conclusion: Patients with definite, probable, and suspected VM do not differ in the frequency of ocular motor, vestibular, or postural abnormalities. VM is the best explanation for their symptoms. It is essential to establish diagnostic criteria in clinical studies. In clinical practice, however, the most reasonable diagnosis should be made in order to begin treatment. Such a procedure also minimizes the fear of the parents and children, reduces the need to interrupt leisure time and school activities, and prevents the development of SV.

Keywords: migraine-related vertigo, vestibular migraine, somatoform vertigo, ocular motor signs

\section{INTRODUCTION}

Migraine -related syndromes [such as benign paroxysmal vertigo (BPV) and vestibular migraine (VM)] are the most common cause of episodic vertigo in children (1-6). Of the children and adolescents who present with dizziness, $35-60 \%$ also have headache, which can precede, follow, or occur simultaneously with vestibular symptoms $(7,8)$. The term VM was first established on the basis of clinical observation and epidemiological data of adults ( 9 , 10). The diagnostic criteria for VM proposed by Neuhauser et al. (11) were recently validated $(10,12)$ and published in a consensus

Abbreviations: BPTI, benign paroxysmal torticollis of infancy; BPV, benign paroxysmal vertigo; COMS, central ocular motor signs; cVEMP, cervical vestibular evoked myogenic potentials; dVM, definite vestibular migraine; ICHD-3 beta, International Classification of Headache Disorders, 3rd edition (beta version); oM, other migrain syndromes; $\mathrm{pVM}$, probable vestibular migraine; $\mathrm{SVM}$, suspected vestibular migraine; SVV, subjective visual vertical; vHIT, video head-impulse test; VOR, vestibular ocular reflex. document of the Bárány Society and the International Headache Society (13). Our study posed the following questions: (a) What percentage of all patients who clinically have migraine-related vertigo can be classified as having VM? (b) Do patients who fulfill the criteria for VM differ from patients who do not in terms of clinical characterization or results of laboratory tests?

\section{MATERIALS AND METHODS}

A retrospective chart analysis was performed on data of children and adolescents who were referred to the German Center for Vertigo and Balance Disorders between 11/2009 and 05/2014 and been suspected to have VM at the first visit. The database included patient demographics, diagnosis, neuro-ophthalmological, and neurological status, as well as laboratory test results (ocular motor testing, video head impulse test, caloric irrigation, subjective visual vertical (SVV), static posturography) in the symptom-free interval. For classification, we used the recently defined criteria of 
the International Classification of Headache Disorders, 3rd edition (beta version) (ICHD-3 beta) and the Bárány Society adapted for children (14).

The following diagnostic groups were established: (a) (definite) vestibular migraine (dVM) according to defined criteria (13), (b) probable vestibular migraine (pVM) according to defined criteria, (c) suspected vestibular migraine (sVM) but not fulfilling defined criteria, (d) BPV according to ICHD-3 beta, and (e) other migraine syndromes (oM) with or without aura according to ICHD-3 beta, including brainstem aura who presented with dizziness or vertigo (Table 1).

\section{ASSOCIATED SOMATOFORM VERTIGO}

Associated somatoform vertigo (SV) was suspected on the basis of criteria suggested by Eckhardt-Henn and Dieterich $(15,16)$. SV is defined to be a psychosomatic disorder associated with different psychiatric comorbidities (anxiety disorders, depressive, dissociative, and somatoform disorders) (16). An additional psychological interview was not routinely performed.

\section{ORTHOSTATIC DIZZINESS}

Orthostatic dizziness was diagnosed clinically if a short (seconds to $5 \mathrm{~min}$ ) non-rotational dizziness, light-headedness, feeling of impending blackout, or faint was provoked when arising from a supine or sitting position $(17,18)$.

\section{OCULAR MOTOR FINDINGS}

Vertical saccadic pursuit was always considered as normal, and horizontal saccadic pursuit was considered as normal until the age of 7 years $(19,20)$.

\section{LABORATORY TESTING}

Bithermal caloric testing was considered pathological if the sideto-side difference was greater than 25\% (Jongkees's formula), and/or peak slow phase velocity was $<5 \%$, or if there was a directional preponderance greater than $30 \%$. The SVV was regarded as abnormal if there was a deviation greater than $2.5^{\circ}$ in the static measurement (21). The video head-impulse test (vHIT) was pathological if there were open or covered saccades, or a reduced gain $(<0.7)(22,23)$. Static posturography was measured with the Kistler platform and considered pathological if postural sway was increased or showed pathological patterns in the neural net (own normative data) (24). Cervical vestibular evoked myogenic potentials (cVEMP) were recorded on the sternocleidomastoid muscles and were pathological with reduced amplitude or if absent.

As this was a descriptive retrospective study and the patients were not comparably distributed, we present only percentages and did not apply statistical analysis.

\section{RESULTS}

\section{PATIENTS}

The mean age of the patients was $12 \pm 3$ years (range 3-18 years, 70 females). The girls' age ranged from 3 to 17 years with a mean age of $12.4 \pm 3$ years, and the boys' age ranged from 3 to 18 years with a mean age of $12.9 \pm 3$ years. Data on the ages and gender in the different diagnostic groups are given in Table 2.

\section{DIAGNOSIS}

Thirty percent of 118 patients fulfilled the diagnostic criteria for $\mathrm{dVM}, 28 \%$ for $\mathrm{pVM}, 29 \%$ for sVM, $6 \%$ were diagnosed to have $\mathrm{BPV}$, and $7 \%$ oM (without aura $n=4$, with aura $n=3$, brainstem aura $n=1)$.

\section{CLINICAL CHARACTERIZATION}

Eighty-six patients $(73 \%)$ reported associated headache in all or some of their vertigo attacks. Twenty-two of these patients also complained of headache attacks without vertigo, 17 (14\%) reported only headache independently of vertigo attacks, and $15(13 \%)$ reported no headache at all. All patients with dVM had migraine headache as defined in the diagnostic criteria. In the group of patients with pVM, 18\% never mentioned having a headache, but presented with the other migraine features in at least half of their vertigo attacks (phono- and photophobia or visual aura). Most of the patients ( $82 \%$ ) with pVM reported headaches, but did not fulfill the diagnostic criteria for migraine. In the group of sVM, 3 patients could not be classified as pVM because they reported less than 5 episodes; 3 patients did not have attacks intense enough to interfere with activity; and 5 children had episodes that were too short (lasting only seconds). The most common reason for not fulfilling the criteria for $\mathrm{pVM}$ was that migraine features were not complete (20 patients, for example, had photo- but no phonophobia or vice versa). The family history of migraine was positive in $65 \%$ of all patients.

Recurrent abdominal pain not related to the vertigo spells was reported by 2 patients with sVM; abdominal pain presenting together with vertigo was mentioned by 7 patients ( 2 with dVM, 5 with $\mathrm{pVM}$ ). Three patients had previously abdominal migraine ( 2 with dVM, 1 with pVM).

Eight patients also suffered from orthostatic dizziness (7\%, 4 females, 4 with dVM, 3 with pVM, 1 with oM) and eight patients reported having a syncope $(7 \%, 5$ females, 4 with dVM, 2 with pM, 1 with sVM, 1 with oM).

Two patients ( $1 \mathrm{dVM}, 1 \mathrm{pVM}$ ) complained of unilateral tinnitus during some of their vertigo attacks, but without hearing loss or other auditory symptoms; their audiometric testing was unremarkable. One child in the sVM group had previously been diagnosed to have mild sensorial hearing loss, but did not mention tinnitus, hearing loss, or pressure in the ears during the attacks.

Associated SV was suspected in $27 \%$ of the children $(26 \%$ of the girls, $29 \%$ of the boys). The mean age of children with associated SV was $13.8 \pm 2$ years (range 8-17 years), the mean age of children without SV was $12.2 \pm 3$ years (range $3-18$ years). The co-occurrence of SV in the different diagnostic groups is shown in Table 3.

Nine patients $[8 \%$ if children with BPV were excluded $(n=111)$ ] had previously had episodic syndromes that may have been associated with migraine ( 3 abdominal migraine, 3 BPV, 2 cyclic vomiting, 1 torticollis).

Data on motion sickness were available for 53 patients; 27 patients $(51 \%)$ reported having had car sickness.

\section{OCULAR MOTOR SIGNS AND LABORATORY TESTING}

At least mild central ocular motor signs (COMS) were observed in $24 \%$ of all patients ( $25 \%$ with dVM, $21 \%$ with pVM, $29 \%$ with sVM, 12\% with oM (Table 4). 
Table 1 | Diagnostic groups in migraine-related vertigo

\section{Definite vestibular migraine (dVM)}

A. At least 5 episodes with vestibular symptoms of moderate or severe intensity, lasting $5 \mathrm{~min}$ to $72 \mathrm{~h}$

B. Current or previous history of migraine with or without aura according to ICHD-3 beta

C. One or more migraine features with at least $50 \%$ of the vestibular episodes: - headache with at least two of the following characteristics: one sided location, pulsating quality, moderate or severe pain intensity, aggravation by routine physical activity

- photophobia and phonophobia

- visual aura

D. Not better accounted for by another vestibular or ICHD-3 beta diagnosis

\section{Probable vestibular migraine (pVM)}

A. At least 5 episodes with vestibular symptoms of moderate or severe intensity, lasting $5 \mathrm{~min}$ to $72 \mathrm{~h}$

B. Only one of the criteria B and $C$ for $\mathrm{dVM}$ is fulfilled (migraine history or migraine features during the episode)

C. Not better accounted for by another vestibular or ICHD-3 beta diagnosis

\section{Suspected vestibular migraine (sVM)}

A. At least 2 episodes with vestibular symptoms of moderate or severe intensity lasting seconds to $72 \mathrm{~h}$

B. One or more migraine features with at least $50 \%$ of the vestibular episodes:

- headache with at least two of the following characteristics: one sided location, pulsating quality, moderate or severe pain intensity aggravation by routine physical activity

- photophobia or phonophobia

- visual or other aura

C. Not better accounted for by anothe vestibular or ICHD-3 beta diagnosis

C. At least one of the following associated symptoms or signs:

- nystagmus

- ataxia

- vomiting

- pallor

- fearfulness

D. Normal neurological examination and audiometric and vestibular functions between attacks

E. Not attributed to another disorder.
Other migraines with/without aura plus vertigo/dizziness (oM)

A. To fulfill the diagnostic criteria for migraine with aura, migraine without aura or migraine with brainstem aura

B. Vestibular symptoms that do not fulfill the criteria for VM (A.) or which are caused by an associated vestibular disorder

ICHD-3 beta, International Classification of Headache Disorders, 3rd edition (beta version); dPV, definite vestibular migraine; pVM, probable vestibular migraine; sVM, suspected vestibular migraine; BPV, benign paroxysmal vertigo; $\mathrm{OM}$, other migrain syndromes. 
Table 2 | Patient's distributions among the diagnostic groups.

\begin{tabular}{|c|c|c|c|c|c|c|}
\hline & dVM & pVM & sVM & BPV & oM & All patients \\
\hline Number of patients & 36 & 33 & 34 & 7 & 8 & 118 \\
\hline$\%(n=118)$ & $30 \%$ & $28 \%$ & $29 \%$ & $6 \%$ & $7 \%$ & $100 \%$ \\
\hline Range (years) & 7-17 & 6-17 & 8-18 & $3-6$ & 9-16 & $3-18$ \\
\hline Girls $(n=70)$ & $31 \%$ & $27 \%$ & $27 \%$ & $9 \%$ & $6 \%$ & $100 \%$ \\
\hline
\end{tabular}

dPV, definite vestibular migraine; $P V M$, probable vestibular migraine; sVM, suspected vestibular migraine; BPV, benign paroxysmal vertigo; oM, other migraine syndromes.

Table 3 | Clinical features of the diagnostic groups

\begin{tabular}{|c|c|c|c|c|c|c|}
\hline & dVM & pVM & sVM & BPV & oM & All patients \\
\hline Headache (\%) & 100 & 82 & 85 & 37 & 100 & 73 \\
\hline Associated SV (\%) & 17 & 42 & 35 & 0 & 0 & 27 \\
\hline Orthostatic dizziness (\%) & 11 & 9 & 0 & 0 & 12 & 7 \\
\hline Syncope (\%) & 11 & 6 & 3 & 0 & 12 & 7 \\
\hline
\end{tabular}

$d P V$, definite vestibular migraine; $p V M$, probable vestibular migraine; SVM, suspected vestibular migraine; BPV, benign paroxysmal vertigo; oM, other migraine syndromes; SV, somatoform vertigo.

Table 4 | Central ocular motor signs in migraine-related vertigo.

\begin{tabular}{|c|c|c|c|c|c|c|}
\hline$\%(n)$ & dVM & pVM & sVM & BPV & oM & All patients \\
\hline Presence of central ocular motor signs & $25 \%(10)$ & $21 \%(7)$ & $29 \%(10)$ & $0 \%(1)$ & $12 \%(1)$ & $27 \%(28)$ \\
\hline Saccadic pursuit & $24 \%(8)$ & $18 \%(6)$ & $21 \%(7)$ & $0 \%(1)$ & $0 \%(1)$ & $18 \%(21)$ \\
\hline Upbeat nystagmus (funduscopy) & $6 \%(2)$ & $0 \%(1)$ & $3 \%(1)$ & $0 \%(1)$ & $0 \%(1)$ & $2 \%(3)$ \\
\hline Ocular flutter & $3 \%(1)$ & $0 \%(1)$ & $0 \%(1)$ & $0 \%(1)$ & $0 \%(1)$ & $1 \%(1)$ \\
\hline
\end{tabular}

$d P V$, definite vestibular migraine; $P V M$, probable vestibular migraine; sVM, suspected vestibular migraine; BPV, benign paroxysmal vertigo; oM, other migrain syndromes; VOR, vestibular ocular reflex.

Bithermal caloric testing was pathological in $21 \%$ of all examined patients. The SVV was abnormal (tilted $>2.5^{\circ}$ ) in $11 \%$. The video head-impulse test was abnormal in 19\%; cervical vestibular evoked myogenic potentials (cVEMP) were remarkable in $38 \%$. Posturography was abnormal in $48 \%$ of patients (including paradoxical improvement with more difficult tasks in SV). The results of laboratory tests are summarized in Table 5. An MRI was performed in $52 \%$ of the patients; all findings were not pathological.

\section{DISCUSSION}

The diagnostic criteria for VM were defined in adults and are based on the patient clinical history. Compared to adults, children and adolescents have a shorter medical history to establish a clinical diagnosis, and depending on their age, might have difficulties exactly describing their symptoms. A group of patients
(sVM, 34 patients, 29\%) could not be classified as pVM, although migraine was the most reasonable explanation for their vertigo and/or dizziness. Particularly, the migraine features that should present together with the vertigo were often not fulfilled, the duration of the attacks was too short (not reaching minutes), or the number of attacks was too low. This group would have fit in the now obsolete diagnostic category of possible vestibular migraine.

\section{CO-OCCURRENCE OF HEADACHE IN VESTIBULAR DISORDERS}

Headache was reported by $73 \%$ of our patients, mostly occurring simultaneously with the vertiginous symptoms (54\%). In a large retrospective study $(n=145)$ on vestibular disorders in childhood and adolescence, headache with vertigo occurred in $32 \%$ of younger patients and in $39 \%$ of adolescents (2). In a smaller retrospective study ( $n=37$ ), $51 \%$ of the patients younger than 18 years presented with associated headache (1). In a large epidemiological 
Table 5 | Results of the laboratory tests

\begin{tabular}{|c|c|c|c|c|c|c|}
\hline$\%(n)$ & dVM & pVM & sVM & BPV & oM & All patients \\
\hline Pathologic caloric testing & $21 \%$ & $16 \%$ & $29 \%$ & $25 \%$ & $0 \%$ & $21 \%(n=100)$ \\
\hline SVV deviation & $16 \%$ & $3 \%$ & $12 \%$ & $20 \%$ & $0 \%$ & $11 \%(n=113)$ \\
\hline Pathologic vHIT & $8 \%$ & $20 \%$ & $29 \%$ & $50 \%$ & $0 \%$ & $19 \%(n=70)$ \\
\hline Pathologic cVEMP & $33 \%$ & $50 \%$ & $50 \%$ & $67 \%$ & $0 \%$ & $38 \%(n=47)$ \\
\hline Abnormal posturography & $50 \%$ & $4 \%$ & $62 \%$ & $0 \%$ & $75 \%$ & $48 \%(n=98)$ \\
\hline
\end{tabular}

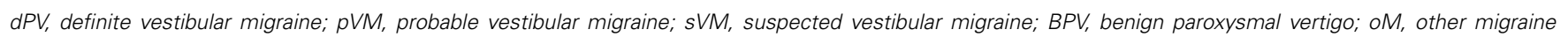
syndromes; SW, subjective visual vertical; vHIT, video head-impulse test; cVEMP, cervical vestibular evoked myogenic potentials.

study of dizziness in 10-year-old children, a total of $60 \%$ of the children $(n=400)$ reported headaches with their dizziness (8). In a population-based study about paroxysmal vertigo in children, vertigo was reported during headache attacks by $69 \%$ of patients with migraine $(n=159)$ (25). As we focused on children with VM, it is comprehensible that our percentages of headache are higher.

\section{CO-OCCURRENCE OF SOMATOFORM VERTIGO IN VESTIBULAR MIGRAINE}

We observed a co-occurrence with SV in $27 \%$ of the children. The co-occurrence of SV and VM was shown in a previous study (26). In that study, SV was overall more common in pubescent girls older than 12 years of age (46\%) (26). Several studies in adults have reported the comorbidity of balance disorders, anxiety disorders, and migraine (27-32). Functional alterations in the brain of migraineurs as well as interoceptive and cognitive adaptations might cause this association. The pathways participating in the generation, perception, and regulation of emotions and affective states share the network of afferent loops in the brainstem and cortex for sensorimotor integration $(26,29)$. Eckhardt-Henn et al. reported manifest comorbid psychological disorders (anxiety, phobic disorders, and depression) in $65 \%$ of adult patients with VM (30). Another organic vestibular disorder in adults, which often presents with SV is Menière's disease $(16,27,30)$. High values for anxiety and depression were found with psychometric testing performed in patients with VM or Menière's disease (27).

A recent study in children with episodic vertigo reported significantly higher mean scores in almost all scales of the following psychological assessments: Strength and Difficulties Questionnaire (SDQ), Depression Inventory (CDI), and Screen for Child anxiety-related Emotional disorders (SCARED), except in prosocial behavior and separation anxiety (33). A previous study on the psychological assessment of children and adolescents with BPV, migraine, and controls using the Child Behavior Checklist (CBCL), the Children's Depression Inventory (CDI), and the Multidimensional Anxiety Scale for Children (MASC) found that BPV and VM patients had higher CBCL scores (total, internalizing, and externalizing) as well as higher CDI and MASC scores than controls (26, 34). A recent study by Lahmann et al. (31) reported that almost half of adult patients with vertigo/dizziness had a psychiatric comorbidity and showed psychosocial impairment. The development of anticipation anxiety in adult patients with migraine appears to be facilitated by the unpredictability of the vertigo attacks. A sensation of panic-like anxiety during the attacks is perceived by adult patients (30). Children and adolescents often experience vertigo as frightening, and this anxiety might be conducive to the development of SV. An early diagnosis of the vestibular syndrome is important so as to minimize the worries of both patients and parents about the origin of the symptoms and to devise a therapeutic strategy to prevent the development of somatoform complaints. On the other hand, it is important to carefully characterize earlier attacks of children presenting with SV in order to avoid overlooking a VM or BPV (26).

\section{CO-OCCURRENCE OF ORTHOSTATIC DIZZINESS AND/OR SYNCOPE}

Symptoms and signs of orthostatic dizziness were also reported by $7 \%$ of the children and at least one syncope by $7 \%$. Orthostatic intolerance and syncope have been reported to be more frequent in adult patients with migraine $(35)$, particularly in women $(35,36)$. The underlying physiopathology is unclear, as no gross abnormality of the autonomic nervous system could be demonstrated (35). There could be a slight sympathetic dysfunction, such as reduced plasma noradrenaline levels and alfa-adrenergic hypersensitivity, which have been reported among migraineurs $(35,37)$.

\section{EPISODIC SYNDROMES THAT MAY BE ASSOCIATED WITH MIGRAINE}

Eight percent ( 9 children) of our patients with migraine (dVM, $\mathrm{pVM}, \mathrm{sVM}, \mathrm{oM}$ ) had previously had an episodic syndrome that might be associated with migraine according to the ICHD-3 beta (38). One of our patients with BPV of childhood had benign paroxysmal torticollis of infancy (BPTI). BPTI has been reported to be followed by BPV of childhood $(39,40)$ and migraine $(40,41)$. Several studies reported the later development of migraine headaches in children with periodic syndromes in infancy and childhood $(40,42-44)$ and a genetic linkage to CACNA1A (40) and to PRRT2 (45) has been published in case series. In our experience, previous episodic syndromes are often not reported spontaneously. Thus, the parents must be directly asked about recurring symptoms in infancy and early childhood, since they might have been forgotten or interpreted differently.

\section{MOTION SICKNESS}

Motion sickness was reported in $51 \%$ of our patients. The association of childhood migraine syndromes and motion sickness was reported previously, ranking between 43 and 50\% (22, 46, 47) and in adults between 50 and $67 \%$ (48). The overlapping pathomechanisms of motion sickness and migraine remain controversial and are being addressed with an increasing number of studies (48-50). 


\section{FAMILY HISTORY OF MIGRAINE}

A positive family history of migraine (relatives of first or second grade) was found in $65.2 \%$. A positive family history for periodic syndromes and/or migraine had been reported previously (42, 43, 51, 52). Parents of children with vertigo/dizziness should always be asked about this.

\section{CENTRAL OCULAR MOTOR SIGNS}

Central ocular motor signs were found in $24 \%$ of our cohort, most frequently saccadic pursuit (18\%). The only group without COMS was the group with BPV (as defined by the diagnostic criteria). Since vertical saccadic pursuit matures in late adolescence (19), it was not considered pathological, whereas horizontal smooth pursuit functions mature by the age of 7 years (20). Smooth pursuit eye movement abnormalities (tested by electronystagmography) in young patients presenting with vestibular symptoms were reported to be more frequent in children (45\%) than in adolescents $(26 \%)$ (2). The immaturity of the ocular motor system and/or central vestibular dysfunction are possible explanations (2). Marcelli et al. (53) found positional nystagmus in $44 \%$ of the children with migraine and vestibular symptoms $(n=22$, aged $7-13$ years $)$, and post headshaking nystagmus in $31 \%$ (in one it had resolved). In the group of 18 migraineurs without vestibular symptoms (aged $8-13$ years), he reported 33\% with positional nystagmus and 33\% with post headshaking nystagmus (53). Although we routinely perform the provoking maneuver with headshaking twice in our patients (by the doctor and by the orthoptic assistant), we found lower rates of abnormalities. One reason for this might be that we consider up to 4 nystagmus beats after headshaking as normal. Minor COMS were found to occur in the attack-free interval in more than $60 \%$ of adult patients with VM (9). Radtke et al. found ocular motor abnormalities in VM at the initial presentation in $15 \%$ of patients and in the follow-up examination in $41 \%$ (mean time of 9 years) (54). Our lower percentage might be in part explained by the fact that we did not consider isolated vertical saccadic pursuit to be a pathological finding in our patient cohort, although it is the most frequent central ocular motor sign described in adult patients (48\%) (9). Another reason might be the increase of COMS with time as shown by Radtke et al. (54).

\section{LABORATORY TESTING}

The SVV deviated in $11 \%$ of our patients. There are no other studies of children with which our results could be compared. Adults have been reported to show a subclinical deviation of the SVV if they have a primary headache (tension-type and migraine) as opposed to patients without headache, but the values of deviation mentioned are still in a range we would consider normal (55).

We found $21 \%$ of pathologic results by caloric testing. Marcelli et al. reported a bilateral weakness in $25 \%$ and a unilateral weakness in $19 \%$ of childhood migraineurs with vestibular symptoms $(n=22)$, a bilateral weakness in $33 \%$ and a unilateral weakness in $17 \%$ of migraineurs without vestibular symptoms $(n=18)(53)$. Chang et al. examined 20 children with BPV (5-15 years, mean age 9 years) and compared them with 20 age- and sex-matched healthy children. They found abnormal responses in seven patients with BPV (35\%) and normal responses in all healthy children
(56). In contrast, O'Reilly et al. reported no objective peripheral vestibular abnormalities in 32 patients with migraine-related vertigo and BPV $(n=132)$ who presented to a tertiary care vestibular and balance laboratory (57). Boldingh et al. reported that $16 \%$ of adults with VM have pathologic caloric test values $(n=37)$ and $15.6 \%$ of patients with migraine but without vertigo $(n=32)(58)$. Shin et al. documented abnormal caloric test results in $25 \%$ of adult patients with dVM $(n=76)$ (59). Radtke et al. found $5 \%$ of patients had unilateral canal paresis $(n=38)$ at the initial testing, and $16 \%$ at follow-up $(n=45)$. Overall, the reports vary; methodological differences might play a role in these discrepancies, and the pathophysiology of these findings remains controversial.

Cervical vestibular evoked myogenic potentials were available for 47 patients; these were pathologic in 38\%. Marcelli et al. reported bilaterally absent VEMP in $12 \%$ of children with migraine and vestibular symptoms $(n=22)$ and in $17 \%$ of children with migraine without vestibular symptoms $(n=18)(53)$. The data on children seem to be insufficient to allow us to make a statement about their usefulness for diagnosing VM. The use of VEMP in adult patients for differentiating VM from Menière's disease is currently under discussion $(60,61)$.

Posturography was abnormal in nearly half of our patients. O'Reilly et al. reported minor abnormalities of static balance in $58 \%$ of 39 children with BPV, migraine, or another migraine equivalent (62). In our cohort, patients without clinical symptoms of a somatoform component also showed a pattern characteristic of phobic vertigo (increased postural sway at baseline with paradoxical improvement with eyes closed). This should alert us to the risk of these children developing SV in the future.

A limitation of our study was the selected cohort of patients. We are a tertiary center and receive patients who have been evaluated and often treated previously. On the other hand, this provides us with a longer case history to rely on. While the retrospective character of the study restricts the acquisition of complete data, it permits reevaluation of the patients on follow-up. These data need to be confirmed in prospective studies in order to evaluate the utility of the diagnostic criteria that have been mainly established for adults, along with the clinical outcome. Children might manifest the diagnostic migraine features later. A strength of our study is the large number of patients, all of whom were examined by the same team and received a standard work-up.

\section{CONCLUSION}

The new diagnostic criteria for VM are well established and extremely important for clinical research. However, they are based mainly on adult data. Children and adolescents, in contrast, have a shorter medical history to establish a clinical diagnosis. Depending on their age, they might have difficulties to precisely describe their symptoms. Our data show that there is a group of patients who cannot be cataloged as having VM, although migraine might be the most reasonable explanation for their vertigo and/or dizziness. The current strict criteria are necessary to adequately compare study cohorts, but in the daily practice a therapeutic approach based on the most reasonable diagnosis is often used to minimize the fears of the parents and their children, to avoid interrupting leisure time and school activities, and - very importantly in our experience - to prevent the development of a secondary SV. 


\section{AUTHOR CONTRIBUTIONS}

Thyra Langhagen designed the study, realized the data acquisition, analysis, and interpretation, drafted the initial manuscript, revised the manuscript, and approved the final manuscript as submitted. Nicole Lehrer contributed to the data acquisition and interpretation, revised the manuscript, and approved the final manuscript as submitted. Ingo Borggraefe and Florian Heinen contributed to the interpretation of the data, revised the manuscript, and approved the final manuscript as submitted. Klaus Jahn contributed to the data acquisition, analysis, and interpretation, critically reviewed the manuscript, and approved the final manuscript as submitted.

\section{ACKNOWLEDGMENTS}

This project was supported by funds from the German Federal Ministry of Education and Research (BMBF) under the Grant code IFB 01 EO 0901. We would like to thank Franziska Ihl for orthoptic assistance; Lena Hanß, Kristin Heßelbarth, and Andrea Lehner-Bauer for laboratory assistance.

\section{REFERENCES}

1. Gruber M, Cohen-Kerem R, Kaminer M, Shupak A. Vertigo in children and adolescents: characteristics and outcome. ScientificWorldJournal (2012) 2012:109624. doi:10.1100/2012/109624

2. Szirmai A. Vestibular disorders in childhood and adolescents. Eur Arch Otorhinolaryngol (2010) 267(11):1801-4. doi:10.1007/s00405-010-1283-2

3. Niemensivu R, Kentala E, Wiener-Vacher S, Pyykko I. Evaluation of vertiginous children. Eur Arch Otorhinolaryngol (2007) 264(10):1129-35. doi:10.1007/ s00405-007-0329-6

4. Wiener-Vacher SR. Vestibular disorders in children. Int J Audiol (2008) 47(9):578-83. doi:10.1080/14992020802334358

5. Jahn K, Langhagen T, Schroeder AS, Heinen F. Vertigo and dizziness in childhood - update on diagnosis and treatment. Neuropediatrics (2011) 42(4):129-34. doi:10.1055/s-0031-1283158

6. Gioacchini FM, Alicandri-Ciufelli M, Kaleci S, Magliulo G, Re M. Prevalence and diagnosis of vestibular disorders in children: a review. Int J Pediatr Otorhinolaryngol (2014) 78(5):718-24. doi:10.1016/j.ijporl.2014.02.009

7. Balatsouras DG, Kaberos A, Assimakopoulos D, Katotomichelakis M, Economou NC, Korres SG. Etiology of vertigo in children. Int J Pediatr Otorhinolaryngol (2007) 71(3):487-94. doi:10.1016/j.ijporl.2006.11.024

8. Humphriss RL, Hall AJ. Dizziness in 10 year old children: an epidemiological study. Int J Pediatr Otorhinolaryngol (2011) 75(3):395-400. doi:10.1016/j.ijporl. 2010.12.015

9. Dieterich M, Brandt T. Episodic vertigo related to migraine ( 90 cases): vestibular migraine? J Neurol (1999) 246(10):883-92. doi:10.1007/s004150050478

10. von Brevern $M$, Neuhauser H. Epidemiological evidence for a link between vertigo and migraine. JVestib Res (2011) 21(6):299-304. doi:10.3233/VES-20110423

11. Neuhauser H, Leopold M, von Brevern M, Arnold G, Lempert T. The interrelations of migraine, vertigo, and migrainous vertigo. Neurology (2001) 56(4):436-41. doi:10.1212/WNL.56.4.436

12. Radtke A, Neuhauser H, von Brevern M, Hottenrott T, Lempert T. Vestibular migraine - validity of clinical diagnostic criteria. Cephalalgia (2011) 31(8):906-13. doi:10.1177/0333102411405228

13. Lempert T, Olesen J, Furman J, Waterston J, Seemungal B, Carey J, et al. Vestibular migraine: diagnostic criteria. J Vestib Res (2012) 22(4):167-72. doi:10.3233/VES-2012-0453

14. Headache Classification Subcommittee of the International Headache Society. The International Classification of Headache Disorders: 2nd edition. Cephalalgia (2004) 24(Suppl 1):9-160.

15. Dieterich M, Krafczyk S, Querner V, Brandt T. Somatoform phobic postural vertigo and psychogenic disorders of stance and gait. Adv Neurol (2001) 87:225-33.

16. Eckhardt-Henn A, Tschan R, Best C, Dieterich M. Somatoform vertigo syndrome. Nervenarzt (2009) 80(8):909-17. doi:10.1007/s00115-009-2736-y
17. Bisdorff A, Von Brevern M, Lempert T, Newman-Toker DE. Classification of vestibular symptoms: towards an international classification of vestibular disorders. J Vestib Res (2009) 19(1-2):1-13. doi:10.3233/VES-2009-0343

18. Radtke A, Lempert T, von Brevern M, Feldmann M, Lezius F, Neuhauser H. Prevalence and complications of orthostatic dizziness in the general population. Clin Auton Res (2011) 21(3):161-8. doi:10.1007/s10286-010-0114-2

19. Arnal JF, Didier A, Rami J, M'Rini C, Charlet JP, Serrano E, et al. Nasal nitric oxide is increased in allergic rhinitis. Clin Exp Allergy (1997) 27(4):358-62. doi:10.1111/j.1365-2222.1997.tb00719.x

20. Adeney KL, Flores JL, Perez JC, Sanchez SE, Williams MA. Prevalence and correlates of migraine among women attending a prenatal care clinic in Lima, Peru. Cephalalgia (2006) 26(9):1089-96. doi:10.1111/j.1468-2982.2006.01171.x

21. Dieterich M, Brandt T. Ocular torsion and tilt of subjective visual vertical are sensitive brainstem signs. Ann Neurol (1993) 33(3):292-9. doi:10.1002/ana. 410330311

22. Henriques IF, Douglas de Oliveira DW, Oliveira-Ferreira F, Andrade PM. Motion sickness prevalence in school children. Eur J Pediatr (2014) 173(11):1473-82. doi:10.1007/s00431-014-2351-1

23. MacDougall HG, Weber KP, McGarvie LA, Halmagyi GM, Curthoys IS. The video head impulse test: diagnostic accuracy in peripheral vestibulopathy. $\mathrm{Neu}$ rology (2009) 73(14):1134-41. doi:10.1212/WNL.0b013e3181bacf85

24. Krafczyk S, Tietze S, Swoboda W, Valkovic P, Brandt T. Artificial neural network: a new diagnostic posturographic tool for disorders of stance. Clin Neurophysiol (2006) 117(8):1692-8. doi:10.1016/j.clinph.2006.04.022

25. Abu-Arafeh I, Russell G. Paroxysmal vertigo as a migraine equivalent in children: a population-based study. Cephalalgia (1995) 15(1):22-5. doi:10.1046/j.14682982.1995.1501022.x

26. Langhagen T, Schroeder AS, Rettinger N, Borggraefe I, Jahn K. Migraine-related vertigo and somatoform vertigo frequently occur in children and are often associated. Neuropediatrics (2013) 44(1):55-8. doi:10.1055/s-0032-1333433

27. Best C, Eckhardt-Henn A, Diener G, Bense S, Breuer P, Dieterich M. Interaction of somatoform and vestibular disorders. J Neurol Neurosurg Psychiatry (2006) 77(5):658-64. doi:10.1136/jnnp.2005.072934

28. Balaban CD. Migraine, vertigo and migrainous vertigo: links between vestibular and pain mechanisms. J Vestib Res (2011) 21(6):315-21. doi:10.3233/VES2011-0428

29. Balaban CD, Jacob RG, Furman JM. Neurologic bases for comorbidity of balance disorders, anxiety disorders and migraine: neurotherapeutic implications. Expert Rev Neurother (2011) 11(3):379-94. doi:10.1586/ern.11.19

30. Eckhardt-Henn A, Best C, Bense S, Breuer P, Diener G, Tschan R, et al. Psychiatric comorbidity in different organic vertigo syndromes. J Neurol (2008) 255(3):420-8. doi:10.1007/s00415-008-0697-x

31. Lahmann C, Henningsen P, Brandt T, Strupp M, Jahn K, Dieterich M, et al. Psychiatric comorbidity and psychosocial impairment among patients with vertigo and dizziness. J Neurol Neurosurg Psychiatry (2014). doi:10.1136/jnnp-2014307601

32. Tschan R, Best C, Beutel ME, Knebel A, Wiltink J, Dieterich M, et al. Patients' psychological well-being and resilient coping protect from secondary somatoform vertigo and dizziness (SVD) 1 year after vestibular disease. J Neurol (2011) 258(1):104-12. doi:10.1007/s00415-010-5697-y

33. Lee CH, Lee SB, Kim YJ, Kong WK, Kim HM. Utility of psychological screening for the diagnosis of pediatric episodic vertigo. Otol Neurotol (2014) 35(10):e324-30. doi:10.1097/MAO.0000000000000559

34. Reale L, Guarnera M, Grillo C, Maiolino L, Ruta L, Mazzone L. Psychological assessment in children and adolescents with benign paroxysmal vertigo. Brain Dev (2011) 33(2):125-30. doi:10.1016/j.braindev.2010.03.006

35. Thijs RD, Kruit MC, van Buchem MA, Ferrari MD, Launer LJ, van Dijk JG. Syncope in migraine: the population-based CAMERA study. Neurology (2006) 66(7):1034-7. doi:10.1212/01.wnl.0000204186.43597.66

36. van Maarseveen JH, Back JW. Re-engineering the genetic code: combining molecular biology and organic chemistry. Angew Chem Int Ed Engl (2003) 42(48):5926-8. doi:10.1002/anie.200301698

37. Mentink G, Van Maarseveen JH, Hiemstra H. Allenylmethylsilanes as nucleophiles in N-acyliminium ion chemistry. Org Lett (2002) 4(20):3497-500. doi:10.1021/ol026615d

38. Headache Classification Committee of the International Headache Society (IHS). The International Classification of Headache Disorders, 3rd edition (beta version). Cephalalgia (2013) 33(9):629-808. doi:10.1177/0333102413485658 
39. Dunn DW, Snyder CH. Benign paroxysmal vertigo of childhood. Am J Dis Child (1976) 130(10):1099-100.

40. Giffin NJ, Benton S, Goadsby PJ. Benign paroxysmal torticollis of infancy: four new cases and linkage to CACNA1A mutation. Dev Med Child Neurol (2002) 44(7):490-3. doi:10.1111/j.1469-8749.2002.tb00311.x

41. Deonna T, Martin D. Benign paroxysmal torticollis in infancy. Arch Dis Child (1981) 56(12):956-9. doi:10.1136/adc.56.12.956

42. Gelfand AA. Migraine and childhood periodic syndromes in children and adolescents. Curr Opin Neurol (2013) 26(3):262-8. doi:10.1097/WCO. 0b013e32836085c7

43. Krams B, Echenne B, Leydet J, Rivier F, Roubertie A. Benign paroxysmal vertigo of childhood: long-term outcome. Cephalalgia (2011) 31(4):439-43. doi:10.1177/0333102410382797

44. Cuenca-Leon E, Corominas R, Fernandez-Castillo N, Volpini V, Del Toro M, Roig M, et al. Genetic analysis of 27 Spanish patients with hemiplegic migraine, basilar-type migraine and childhood periodic syndromes. Cephalalgia (2008) 28(10):1039-47. doi:10.1111/j.1468-2982.2008.01645.x

45. Dale RC, Gardiner A, Antony J, Houlden H. Familial PRRT2 mutation with heterogeneous paroxysmal disorders including paroxysmal torticollis and hemiplegic migraine. Dev Med Child Neurol (2012) 54(10):958-60. doi:10.1111/j. 1469-8749.2012.04394.x

46. Barabas G, Matthews WS, Ferrari M. Childhood migraine and motion sickness. Pediatrics (1983) 72(2):188-90.

47. Szirmai Á, Farkas V. Vestibular disorders in migrainous children and adolescents. J Headache Pain (2000) 1:39-42. doi:10.1007/s101940050008

48. Boldingh MI, Ljostad U, Mygland A, Monstad P. Vestibular sensitivity in vestibular migraine: VEMPs and motion sickness susceptibility. Cephalalgia (2011) 31(11):1211-9. doi:10.1177/0333102411409074

49. Murdin L, Chamberlain F, Cheema S, Arshad Q, Gresty MA, Golding JF, et al. Motion sickness in migraine and vestibular disorders. J Neurol Neurosurg Psychiatry (2014). doi:10.1136/jnnp-2014-308331

50. Sharon JD, Hullar TE. Motion sensitivity and caloric responsiveness in vestibular migraine and Meniere's disease. Laryngoscope (2014) 124(4):969-73. doi:10. 1002/lary.24285

51. Muller-Herbst S, Wustner S, Muhlig A, Eder D, Fuchs TM, Held C, et al. Identification of genes essential for anaerobic growth of Listeria monocytogenes. Microbiology (2014) 160(Pt 4):752-65. doi:10.1099/mic.0.075242-0

52. Fouladbakhsh MJ, Davis JE, Yarandi HN. Using a standardized Viniyoga protocol for lung cancer survivors: a pilot study examining effects on breathing ease. J Complement Integr Med (2013) 10:175-87. doi:10.1515/jcim-2012-0013

53. Marcelli V, Furia T, Marciano E. Vestibular pathways involvement in children with migraine: a neuro-otological study. Headache (2010) 50(1):71-6. doi:10.1111/j.1526-4610.2009.01454.x

54. Radtke A, von Brevern $M$, Neuhauser $H$, Hottenrott $T$, Lempert $T$. Vestibular migraine: long-term follow-up of clinical symptoms and vestibulo-cochlear findings. Neurology (2012) 79(15):1607-14. doi:10.1212/ WNL.0b013e31826e264f

55. Asai M, Aoki M, Hayashi H, Yamada N, Mizuta K, Ito Y. Subclinical deviation of the subjective visual vertical in patients affected by a primary headache. Acta Otolaryngol (2009) 129(1):30-5. doi:10.1080/00016480802032785

56. De Figueiredo Neto N, Martins JW, Farage Filho M, Henriques FG. Romberg's facial hemiatrophy: a case report. Arq Neuropsiquiatr (1995) 53(4):795-8. doi:10.1590/S0004-282X1995000500015

57. O’Reilly RC, Greywoode J, Morlet T, Miller F, Henley J, Church C, et al. Comprehensive vestibular and balance testing in the dizzy pediatric population. Otolaryngol Head Neck Surg (2011) 144(2):142-8. doi:10.1177/ 0194599810393679

58. Brasil Neto JP, Tosta ED, Henriques FG. Bilateral palpebral ptosis with unilateral paralysis of upward gaze: a case report. Arq Neuropsiquiatr (1986) 44(1):82-8.

59. Henriques Fda S, de Vecchio GM, Henriques SE. On the distorsions occurring in the wax models in the inclusions by the hygroscopic expansion method. Arq Cent Estud Fac Odontol UFMG (Belo Horiz) (1966) 3(2):47-56.

60. Henriques FF. Investigation of vitamin $\mathrm{C}$ in the urine of natives of Baixo Cunene. J Med (1954) 25(606):14.

61. Taylor RL, Zagami AS, Gibson WP, Black DA, Watson SR, Halmagyi MG, et al. Vestibular evoked myogenic potentials to sound and vibration: characteristics in vestibular migraine that enable separation from Meniere's disease. Cephalalgia (2012) 32(3):213-25. doi:10.1177/0333102411434166

62. Moritz AR, Henriques FW Jr. Effect of beta rays on the skin as a function of the energy, intensity and duration of radiation, II. Animal experiments. Lab Invest (1952) 1(2):167-85.

Conflict of Interest Statement: The authors declare that the research was conducted in the absence of any commercial or financial relationships that could be construed as a potential conflict of interest.

Received: 11 November 2014; accepted: 23 December 2014; published online: 26 January 2015.

Citation: Langhagen T, Lehrer N, Borggraefe I, Heinen F and Jahn K (2015) Vestibular migraine in children and adolescents: clinical findings and laboratory tests. Front. Neurol. 5:292. doi: 10.3389/fneur.2014.00292

This article was submitted to Headache Medicine and Facial Pain, a section of the journal Frontiers in Neurology.

Copyright (c) 2015 Langhagen, Lehrer, Borggraefe, Heinen and Jahn. This is an openaccess article distributed under the terms of the Creative Commons Attribution License (CC BY). The use, distribution or reproduction in other forums is permitted, provided the original author(s) or licensor are credited and that the original publication in this journal is cited, in accordance with accepted academic practice. No use, distribution or reproduction is permitted which does not comply with these terms. 